\title{
The relationship between consciousness and vital living force through the consciousness model
}

\author{
Dhananjay Pal \\ Pharmacy College, Bengal School of Technology, Sugandha-Delhi Road, Chuchura, Dist.-Hooghly, West Bengal, INDIA
}

Email address:

dhananjay.pal123@gmail.com,paldhananjay46@yahoo.com

\section{To cite this article:}

Dhananjay Pal. The Relationship between Consciousness and Vital Living Force through the Consciousness Model. American Journal of Modern Physics. Vol. 3, No. 1, 2014, pp. 1-7. doi: 10.11648/j.ajmp.20140301.11

\begin{abstract}
A single field emerged at the origin of the universe, already containing within itself the blueprint of the physical universe. The primordial single field triggered the onset of the universe. Most physicists believe that a single super-force dominated the first instants of creation. Scientists have arrived at a simple but decisive conclusion that consciousness is very much a part of the universe, like other objects. Our consciousness model involving thought-carrying particle (TCP), thought retaining particle (TRP) and thought force $\left(\mathrm{T}_{\mathrm{F}}\right)$ signifies the existence of universal consciousness that exists along with the universe. This universal consciousness is a functional state of the universal mind (UM). This UM is evolved at the Big Bang from void. The UM is constituted by these TCP and TRP in the inherent presence of thought force $\left(\mathrm{T}_{\mathrm{F}}\right)$. Thought force $\left(\mathrm{T}_{\mathrm{F}}\right)$ is an expression of universal consciousness. The Thought force $\left(\mathrm{T}_{\mathrm{F}}\right)$ being the primordial quantum field functions as the original super-force. $\mathrm{T}_{\mathrm{F}}$ being the original super-force functions as the origin of all the fundamental fields. TCP is the carrier of thought force $\left(\mathrm{T}_{\mathrm{F}}\right)$ that, in turn, appears to be the origin of all the fields. The quantized energy $\left(\varepsilon_{T}\right)$ of TCP is responsible to cause the universal consciousness as well as the cosmic microwave background radiation temperature. The individual consciousness owes its origin to the universal consciousness created by the same $\varepsilon_{T}$. The same $\varepsilon_{T}$ is the energy responsible for generating thought force $\left(\mathrm{T}_{\mathrm{F}}\right) . \mathrm{T}_{\mathrm{F}}$ being an expression of the universal consciousness is applicable to any inanimate object as well as to any biological system (having thinking ability). The $\mathrm{T}_{\mathrm{F}}$ exerts its functions both in vitro and in vivo. These TCP, TRP and the thought force $\left(\mathrm{T}_{\mathrm{F}}\right)$ in vitro and thought force $\left(\mathrm{T}_{\mathrm{F}}\right)$ in vivo provide guidelines to form a relationship between consciousness and vital living force.
\end{abstract}

Keywords: Void, Cosmic Microwave Background Radiation (CMBR), Universal Mind (UM), Thought Force ( $\mathrm{T}_{\mathrm{F}}$ ), Though-Carrying Particle (TCP), Thought Retaining Particle (TRP), Quantized Energy $\left(\varepsilon_{T}\right)$ of TCP

\section{Introduction}

In Eastern philosophical traditions, consciousness is intrinsic to the universe, whereas in most Western views, consciousness is extrinsic, emerging from complex computation. How can these views be reconciled?

It is most relevant and important to indicate the names of various eminent physicists like Erwin Schrödinger, Eugene Wigner, Brian Josephson, John Wheeler, Roger Penrose, Henry P Stapp, Freeman J. Dyson, Paul Davies, David Bohm, Basil Hiley, Fritjof Capra, Fred Alan Wolf and Amit Goswami who have addressed the inclusion of consciousness in their work. Consciousness is to be taken into account.

1.1. In contrast to the usual linear sequence of matter, body, life, brain, mind, consciousness, here the proposed cyclic sequence is first universal consciousness (a functional state of the universal mind), and then matter, body, life, brain, and regeneration of mind and consciousness. The evolution of life with mind and consciousness is possible purely due to the inherent existence of universal consciousness which exists along with the universe. The human nervous system is evolved to provide an appropriate material structure to individualize the universal consciousness, a characteristic of reality, pervading all manifestations.

Consciousness model of Pal et al [1-3] involving TCP, TRP and thought force $\left(\mathrm{T}_{\mathrm{F}}\right)$ signifies the existence of universal consciousness that exists along with the universe. Pal et al [3] showed that this universal consciousness is a functional state of Universal Mind (UM). Pal et al [3] explained that the UM is evolved at the Big Bang from the 
eternal Void. This Void, in turn, is the source of infinite energy. And this UM is a finer matter. The individual mind being a constituent of the UM is also a finer matter. The constituents of the UM and individual mind are the same. The ultimate constituents of matter and mind are the same as both mind and matter are aspects of one fundamental reality, which is called UM. The brain is the mediating link or interface between the individual mind and body.

Pal et al [3] explained that the constituents of the UM are the ultimate constituents of matter itself as everything in this universe is a manifestation of this UM. Pal et al [3] expressed that the UM is constituted by these TCP and TRP in the inherent presence of thought force $\left(\mathrm{T}_{\mathrm{F}}\right)$. Pal et al $[1,3]$ further explained that the ultimate constituents of matter and mind are these TCP and TRP in the inherent presence of thought force $\left(\mathrm{T}_{\mathrm{F}}\right)$ in vitro and thought force $\left(\mathrm{T}_{\mathrm{F}}\right)$ in vivo.

Physicists determined that underlying quantum fields give birth to elementary particles. Bhaumik [4] mentioned that Frank Wilczek pointed out, "In quantum field theory, the primary elements of reality are not individual particles, but underlying fields. Thus, for example, all electrons are but excitations of an underlying field, naturally called electric field". The same holds true for all the fundamental particles of which matter is made.

The existence of matter depends on the existence of force and vice versa. TCP cannot exist without TRP and vice versa. Many physicists believe that unifying all the forces, including gravity, into a single theory would require a phenomenon called super-symmetry. With supersymmetry, every fermion would have a boson twin, and vice-versa. The thought force $\left(\mathrm{T}_{\mathrm{F}}\right)$ is carried by the TCP in the presence of its super-symmetrical partner TRP. TCP that behaves like boson should accompany its supersymmetrical partner TRP that functions like fermion in the generalized simpler way. It is to be noted that these TCP and TRP function like wavicle: wave-particle duality.

\section{Thought Force}

Pal et al [1,3] and Pal [5] explained the existence of thought force $\left(\mathrm{T}_{\mathrm{F}}\right)$. Thought force $\left(\mathrm{T}_{\mathrm{F}}\right)$, an expression of the universal consciousness, is the primordial quantum field that, in turn, functions as the primary unified field. This $T_{F}$ being an expression of the universal consciousness is applicable to any inanimate object as well as to any biological system (having thinking ability). Thus the $T_{F}$ being an expression of the universal consciousness exerts its functions both in vitro and in vivo.

Physicists determined that underlying quantum fields give birth to elementary particles. Pal [5] expressed that the thought force $\left(\mathrm{T}_{\mathrm{F}}\right)$ is the primordial quantum field. Thought force $\left(T_{F}\right)$ being the primordial quantum field functions as the primary unified field. Thought force $\left(\mathrm{T}_{\mathrm{F}}\right)$ being the primordial quantum field gives birth to TRP that appears to be the origin of all the matter particles. TCP is the carrier of thought force $\left(\mathrm{T}_{\mathrm{F}}\right)$ that, in turn, appears to be the origin of all the fields. TCP thus appears to be the origin of all the field particles.

In a purpose to involve both the non-living and living systems of the world, Pal [5] has shown the existences of these TCP, TRP and thought force $\left(\mathrm{T}_{\mathrm{F}}\right)$ in vitro and thought force $\left(\mathrm{T}_{\mathrm{F}}\right)$ in vivo. Anyone can call this TCP by any other name, but as the highly developed living system will have to be evolved in the universe in the long run and as the thought of highly developed living system appears to be a kind of force to be called the thought force $\left(\mathrm{T}_{\mathrm{F}}\right)$ in vivo, we considered it is wise to call it as TCP. Further, as the universe exists along with the universal consciousness that, in turn, is created by the quantized energy $\left(\varepsilon_{T}\right)$ of TCP, we had to use the term TCP.

Pal (5) expressed that the non-living system of the world is governed by the thought force $\left(\mathrm{T}_{\mathrm{F}}\right)$ in vitro and this Thought force $\left(\mathrm{T}_{\mathrm{F}}\right)$ in vitro gives rise to $\mathrm{T}_{\mathrm{F}}$ (micro), $\mathrm{SNF}$, EMF, WNF, GF and $\mathrm{T}_{\mathrm{F}}$ (macro) where $\mathrm{T}_{\mathrm{F}}$ (micro) $=$ Thought force in microcosm, $\mathrm{SNF}=$ Strong nuclear force, $\mathrm{EMF}=$ Electromagnetic force, $\mathrm{WNF}=$ Weak nuclear force, $\mathrm{GF}=$ Gravitational force and $\mathrm{T}_{\mathrm{F}}$ (macro) $=$ Thought force in macrocosm. It is to be noted here that $\mathrm{T}_{\mathrm{F}}$ (micro) is a stronger force than the SNF and $\mathrm{T}_{\mathrm{F}}$ (macro) is a weaker force even than the GF.

Pal (5) also expressed that the living system of the world is governed by the thought force $\left(\mathrm{T}_{\mathrm{F}}\right)$ in vivo and this Thought force $\left(\mathrm{T}_{\mathrm{F}}\right)$ in vivo is a type of force that represents the biological 'thought' which is the action of mind. This 'thought' being a type of force controls the 'thought processes' involving the firing of neurons through the quantum mechanical activities of these TCP and TRP in the presence of consciousness. Consciousness in living organisms is a process which involves the quantum mechanical activities of these TCP and TRP, the ultimate constituents of any matter as well as any mind in the inherent presence of thought force $\left(\mathrm{T}_{\mathrm{F}}\right)$ in vitro and the thought force $\left(\mathrm{T}_{\mathrm{F}}\right)$ in vivo as indicated by Pal et al [3]. This consciousness, in turn, is the quantized energy $\left(\varepsilon_{T}\right)$ of TCP. The thought force $\left(\mathrm{T}_{\mathrm{F}}\right)$ in vivo is demonstrated in numerous experiments in which thought has an effect on a physical process (often known as mind over matter). This biological 'thought' is a type of force that can cause movement. Controlling movement through thought alone is observed in several experiments conducted by many scientists as indicated by Pal (5). These experiments thus signify the existence of thought force $\left(\mathrm{T}_{\mathrm{F}}\right)$ in vivo.

Pal [5] explained the existence of $\mathrm{T}_{\mathrm{F}}$ (micro) (= Thought force in microcosm). This $\mathrm{T}_{\mathrm{F}}$ (micro) is the strongest interaction (a new class of 'extra strong' interaction). It is stronger than SNF (Strong Nuclear Force).

Pal [5] has also shown the existence of $\mathrm{T}_{\mathrm{F}}$ (macro) (= Thought force in macrocosm). It is the "weakest force" which is much weaker even than the gravity.

2.1. Pal et al [3] developed three different equations expressing the quantized energy ( $\mathcal{E}_{T}$ ) of TCP. The value of $\mathcal{E}_{T}$ in one of the three equations is shown below: 


$$
\mathcal{E}_{T}=4.384 \times 10^{-16} \mathrm{erg} \equiv 2.73 \times 10^{-4} \mathrm{eV} \equiv 2.73 \mathrm{~K} \cong C M B R \text { temperature } \equiv 2.725 \mathrm{~K} .
$$

This conversion of erg $\equiv \mathrm{eV} \equiv \mathrm{K}$ is given by Weisskopf [6] as follows:
2.2. Pal et al [3] expressed that the CMBR temperature is due to $\varepsilon_{T}$, the quantized energy of TCP where

$$
\begin{aligned}
& 1 \mathrm{erg} \cong 0.6241807 \times 10^{12} \mathrm{eV} \text { and } 10^{-4} \mathrm{eV} \cong 1 \mathrm{~K} \\
& \varepsilon_{T}=4.384 \times 10^{-16} \mathrm{erg} \equiv 2.73 \times 10^{-4} \mathrm{eV} \equiv 2.73 \mathrm{~K} \cong C M B R \text { temperature } \equiv 2.725 \mathrm{~K} .
\end{aligned}
$$

As per Pal et al [3], it is interesting to note that all of the three different equations ultimately give rise to the same result that is equivalent to the CMBR temperature. A sort of relationship is thus observed between the $\varepsilon_{T}$ and the CMBR temperature. This coincidence is thus signifying a probable role of TCP on the maintenance of CMBR temperature. Further, this coincidence is also signifying the existence of these TCP in the presence of TRP. TCP cannot exist without TRP and vice versa. The presence of TCP, TRP and Thought force $\left(T_{F}\right)$ in the universe is thus indicated and expressed mathematically. At present we are unable to explain when and how these TCP and TRP decoupled from the primordial cosmic soup.

$\mathrm{Pal}$ et al $[1,3]$ showed that the quantized energy $\left(\varepsilon_{T}\right)$ of TCP is responsible to cause the universal consciousness as well as the cosmic microwave background radiation temperature. The individual consciousness owes its origin to the universal consciousness created by the same $\varepsilon_{T}$.

Ultimately this $\varepsilon_{T}$ represents universal consciousness. The existence of CMBR temperature indicates the existence of the TCP in the presence of TRP. The existence of TCP ensures the existence of the thought force $\left(\mathrm{T}_{\mathrm{F}}\right)$. Further, this $\mathrm{T}_{\mathrm{F}}$ being an expression of the quantized energy $\left(\boldsymbol{\varepsilon}_{T}\right)$ of $\mathrm{TCP}$ exerts its functions both in vitro and in vivo.

\section{What is Life?}

Life is a state of flux that is being maintained by a typical form of energy which is nothing but the consciousness itself. Pal et al [3] and Pal [7] showed that the quantized energy $\left(\varepsilon_{T}\right)$ of TCP is responsible to cause the universal consciousness as well as the cosmic microwave background radiation temperature. The individual consciousness owes its origin to the universal consciousness created by the same $\varepsilon_{T}$. Pal et al $[1,3]$ and Pal [7] explained that life may be defined as a state of functional manifestation of consciousness that, in turn, is the quantized energy ( $\varepsilon_{T}$ ) of TCP. This $\varepsilon_{T}$ represents universal consciousness.

Thus,

$$
\text { Life }=\mathrm{f}(\text { Consciousness })=\mathrm{f}\left(\varepsilon_{T}\right)
$$

where $\varepsilon_{T}=$ quantized energy of the TCP $=4.384 \times 10^{-16} \mathrm{erg}$.

$$
\varepsilon_{T}=h v_{T}=h c / \lambda_{T}=4.384 \times 10^{-16} \mathrm{erg}
$$

where

$$
\begin{aligned}
& \varepsilon_{T}=\text { quantized energy of the TCP }=4.384 \times 10^{-16} \mathrm{erg}, \\
& v_{T}=\text { frequency of the TCP }=\varepsilon_{T} / h=66.12 \times 10^{9} \mathrm{~Hz} .=66.12 \mathrm{GHz}, \\
& \mathrm{h}=\text { Planck's quantum constant }=6.63 \times 10^{-27} \mathrm{erg} \cdot \mathrm{sec}, \\
& \mathrm{c}=\text { free-space velocity of light }=3 \times 10^{10} \mathrm{~cm} / \mathrm{sec}, \\
& \lambda_{T}=\text { wave-length of the } \mathrm{TCP}=0.4537 \mathrm{~cm} .
\end{aligned}
$$

\subsection{What is Consciousness?}

Psychologists, neuroscientists, philosophers, and other professionals continue to engage in an ongoing debate as to what consciousness means. In reality, we may never know. Is it a product of the biological and classical physical interactions of the human brain; or is it something more fundamental, perhaps electromagnetic, or the result of quantum physics principles that we don't yet fully understand? Could it be something even more profound than that -- something beyond the scope of science and physics, any kind of physics, for us to understand?

According to the ancient Vedanta, consciousness is not an emergent property of matter that comes into existence only through the functioning of the human nervous system. Instead, consciousness is a characteristic of reality, pervading all manifestations. This unbounded field of nature's universal consciousness is not limited to an individual consciousness. From this viewpoint, the role of the human nervous system is to provide an appropriate material structure to individualize the universal consciousness. It appears that inanimate matter itself cannot generate consciousness without the inherent existence of universal consciousness.

Pal et al [2] explained, "Consciousness is the realization of existence, and there are as many states of consciousness as there are states of existence. Every living being has a consciousness of its own depending on complexity of the brain and the activity of the viable numbers of TCP in the presence of TRP; and the state of its consciousness changes every moment of time. Consciousness is the perception of the relation it bears to things and as this relation changes, consciousness changes its character. Consciousness itself does not change; it only moves up and down on the 'scale of the realization' of existence through the 'sub-conscious', 'conscious' and 'super-conscious' states". There is another term called unconscious state. The most usual unconscious state is sleep. A deeper form of unconsciousness is called a coma. 


\subsection{Possible Relation of Consciousness with Mind: Possible Relation of Animate with Inanimate Through Consciousness}

Modern scientists have not even been able to arrive at a consensus on what should be a definition of the totality of consciousness. The brain is intricately linked to the process of consciousness and consciousness is thought to be a phenomenon of the mind.

It appears that

$$
\text { Consciousness }=\mathrm{f}(\text { mind })
$$

Consciousness is the functional state of mind. Presence of consciousness signifies the presence of mind and vice versa.

It is apparent that

$$
\text { Animate } \neq \text { Inanimate }
$$

Three critical factors which distinguish life from nonliving are consciousness, metabolism and reproduction. (4):

In a gross presentation, we can express from the equation

$$
\text { Animate }- \text { Consciousness }=\text { Inanimate }
$$

Scientists would have to define and characterize consciousness properly. We should have the proper knowledge about the exact characteristics of consciousness in order to address many present day scientific enigmas.

\subsection{Consciousness may be Defined as the 'Self- Organized' Capability of any Living being to Activate TCP and TRP}

Pal et al [3] expressed that consciousness may be defined as the 'self-organized' capability of any living being to activate TCP and TRP, the ultimate constituents of mind and matter and to exert its functions. What can generate, maintain and activate TCP and TRP is called animate having 'active consciousness' and what cannot is called inanimate, i.e., devoid of active consciousness. As anything inanimate does neither have the power to activate the TCP and TRP nor have the capability to catalyze the activity of TCP and TRP, so it cannot generate consciousness. On the contrary, anything animate has the 'self-organized' power to generate, activate and catalyze the activity of TCP and TRP in order to generate and maintain consciousness along with the vital living force. Prigogine et al [8] explained "Self-Organization in Non-Equilibrium Systems".

Consciousness in living organisms is a process which involves the quantum mechanical activities of these TCP and TRP, the ultimate constituents of any matter as well as any mind in the inherent presence of thought force $\left(\mathrm{T}_{\mathrm{F}}\right)$ in vitro and the thought force $\left(\mathrm{T}_{\mathrm{F}}\right)$ in vivo as indicated by $\mathrm{Pal}$ et al $[1,3]$. And these TCP and TRP govern the activities of neurons (not the other way round). Neurons are simply the equipments used to generate consciousness and awareness. The consciousness itself is functioning as an inter-linking agent between the animate and inanimate through the quantum mechanical activities of these TCP and TRP indicated by [3].

\section{Existence of Universal Consciousness}

Pal et al [3] and Pal [7] showed the existence of universal consciousness and explained that the quantized energy $\left(\varepsilon_{T}\right)$ of TCP is responsible to cause the universal consciousness as well as the cosmic microwave background radiation temperature. The individual consciousness owes its origin to the universal consciousness created by the same $\varepsilon_{T}$.

Pal et al [3] have expressed that according to the modern physicists, the universe is the summation of fields, particles, space-time continuum, dark matter, dark energy, void and all the known and unknown parameters of the universe along with all its inhabitants (with or without consciousness), although the universe is always expanding.

The method of integration indicates that

$$
\int d x=x+c
$$

where $\mathrm{c}=\mathrm{a}$ constant. Is there any mathematical fallacy if we like to use 'universe' in the place of ' $x$ ' here? If we at all theoretically like to apply the same method of integration to the whole universe itself, we will have to arrive at

$$
\int d(\text { universe })=\text { universe }+c
$$

where universe $=$ universe with all its known and unknown parameters as well as its inhabitants (with or without consciousness) and $\mathrm{c}=\mathrm{a}$ constant. The constituents of the universe are fields, particles, space-time continuum, dark matter, dark energy, void, all its inhabitants (with or without consciousness) and all the other unknown parameters of the universe that we have not yet faced. We simply propose to apply the method of integration theoretically over the universe as a whole with all its known and unknown parameters and all the inhabitants (with or without consciousness). If we at all theoretically like to do so, we will mathematically arrive at a constant.

What is this constant here? It is our opinion that this constant is the universal consciousness that exists throughout the universe in the form of universe wide web (uww) covering fields, particles, space-time continuum, dark matter, dark energy, void and all its known and unknown parameters along with all its inhabitants (with or without consciousness). This universal consciousness is to be taken into account, but usually ignored.

Many physicists agree with the idea that consciousness is non-local, fundamental in the universe and consciousness is very much a part of the universe, like other objects. It is to be noted that $\mathcal{E}_{T}$, the quantized energy of TCP represents universal consciousness.

Nelson [9], Director of Global Consciousness Project, has observed through the experimentation that coherent consciousness creates order in the world; and subtle interactions link us with each other and the Earth. When human consciousness becomes coherent and synchronized, the behavior of random systems may change. Quantum event based random number generators (RNGs) produce 
completely unpredictable sequences of zeroes and ones. But when a great event synchronizes the feelings of millions of people, our network of RNGs becomes subtly structured. The probability is less than one in a billion that the effect is due to chance. The evidence suggests an emerging noosphere, or the unifying field of consciousness described by sages in all cultures. This evidence signifies and proves the existence of universal consciousness.

The existence of universal consciousness is explained by Radin [10] through experimentation as it is expressed in his book The Conscious Universe: The Scientific Truth of Psychic Phenomena. Further, Consciousness, not matter, is the ground of all existence, declares University of Oregon physicist Goswami through his published (1993) book, "The Self-Aware Universe: How Consciousness Creates the Material World".

As per Penrose [11], consciousness is a part of the universe. Van De Bogart [12] explained, "Since consciousness is a part of the universe it then follows that all consciousness, and the universe, are of the same matrix of energy fields".

\section{The Relationship between Consciousness and Vital Living Force

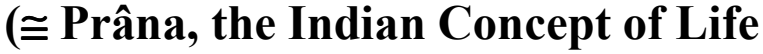 Energies)}

Fritjof Capra [13] expressed, "Both kinds of interconnectedness---that between mind and body and that between organism and environment---would have to be interpreted in terms of tentative notions of energy patterns. The Indian concept of 'Prâna' and the Chinese concept of ch'i are to be taken into account as examples of traditional terms referring to these 'subtle energies', or 'life energies'. In these traditional disciplines illness is seen as resulting from changes in the patterns of energy and therapeutic techniques have been developed to influence the body's energy system".

According to the ancient Indian Vedanta, this Universe is composed of 'Âkâsha' and 'Prâna' as indicated by Vivekananda [14]. 'Âkâsha' is the origin of all the observable matter. And 'Prâna' is the origin of all the natural fields along with vibrations (Thought). This natural field includes the 'vital living force' which, in turn, controls all the psychological as well as the physiological functions of all living beings of the universe. It is to be noted that this Prâna $\cong$ the Indian concept of 'life energies'. And this vital living force as well as the thought force is usually ignored.

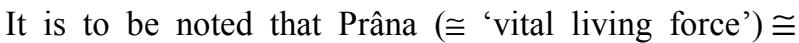
thought force $\left(\mathrm{T}_{\mathrm{F}}\right)$ in vitro + thought force $\left(\mathrm{T}_{\mathrm{F}}\right)$ in vivo $+\mathrm{T}_{\mathrm{F}}$ (micro) $+\mathrm{T}_{\mathrm{F}}$ (macro).

Pal [5] explained vividly the existence of thought force $\left(\mathrm{T}_{\mathrm{F}}\right)$ in vitro and thought force $\left(\mathrm{T}_{\mathrm{F}}\right)$ in vivo and other characteristics of thought force $\left(\mathrm{T}_{\mathrm{F}}\right)$.

Is the physical body of a living being cause of

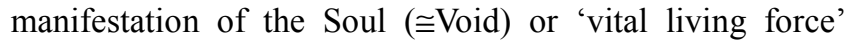
(called Prâna, the Indian concept of 'life energies')? What makes this body? What force causes the atoms to combine in a specific sequence and takes up specific atoms from the mass of matter around us in order to provide different shapes of different species of specific bodies of living beings? It is logical to say that the force which makes up the matter and forms the body, is the same force which is responsible for causing and maintaining the psychological as well physiological functions of the living organisms. This specific force is called "Prâna", the Indian concept of 'life energies'. The sum-total of the energy displayed in the universe is called Prâna indicated by Vivekananda [14]. This Prâna is thought to be the 'universal power'. The Prâna is the gross origin of all the fundamental fields including the 'vital living force' which controls all the psychological as well as the physiological functions of all living beings of the universe. TCP is the force-carrying particle of the original thought force $\left(\mathrm{T}_{\mathrm{F}}\right)$ which is the origin of all the existing natural fields. Thus, this "Prâna" is more or less equivalent to the original thought force $\left(T_{F}\right)$ which is carried by TCP in the inherent presence of TRP. Does this Prâna generate consciousness? Or does the consciousness create Prâna? Are they inter-dependent or intra-dependent? It is apparent that the consciousness being a typical form of energy can initiate the function of Prâna. Life may be defined as a state of functional manifestation of consciousness that, in turn, is the quantized energy $\left(\mathcal{E}_{T}\right)$ of the TCP. This $\varepsilon_{T}$ represents consciousness.

As a separate entity, the Prâna as well as consciousness appears to be independent or they may appear to be interdependent; but, after the initiation of the function of Prâna in a living organism, they are intra-dependent. Thus, when this specific 'vital living force' is eliminated from the living organism, then that living being is said to die.

Pal [5] expressed that the thought force $\left(T_{F}\right)$ being the primordial quantum field functions as the original single primary unified field that is not only the origin of all the four fundamental fields along with both the $\mathrm{T}_{\mathrm{F}}$ (micro) and $\mathrm{T}_{\mathrm{F}}$ (macro) but also the origin of thought force $\left(\mathrm{T}_{\mathrm{F}}\right)$ in vivo.

Thus, the original thought force $\left(\mathrm{T}_{\mathrm{F}}\right)$ which is the primordial quantum field and which is an expression of the universal consciousness represents 'Prâna' that, in turn, is the origin of all the natural fields (including the vital living force) and TRP represents 'Âkâsha'. This 'Prâna' is manifested as nerve-current as well as the biological 'thought force' also. And all the psychological and physiological activities are controlled and maintained by this same 'Prâna' itself.

The "Prâna" is the grosser form of the original thought force $\left(\mathrm{T}_{\mathrm{F}}\right)$; thus its energy should be the quantized energy $\left(\mathcal{E}_{T}\right)$ of TCP as it is expressed by Pal $[5,15]$ through the evolution of universe from the void:

$$
\text { Void } \rightarrow \mathrm{E}_{\mathrm{T}}=\varepsilon_{T}=\mathrm{m}_{\mathrm{T}} \mathrm{c}^{2}=\mathrm{h} \nu_{\mathrm{T}}=\mathrm{hc} / \lambda_{\mathrm{T}}=4.95 \times 10-16 \mathrm{erg}
$$

where,

$\mathrm{E}_{\mathrm{T}}=$ total energy of the universe,

$\mathcal{E}_{T}=$ quantized energy of the TCP $=4.95 \times 10^{-16} \mathrm{erg}$

$\mathrm{m}_{\mathrm{T}}=$ quantized mass of the $\mathrm{TCP}=\varepsilon_{T} / \mathrm{c}^{2}=5.5 \times 10^{-37} \mathrm{~g}$, 
$\mathrm{h}=$ Planck's quantum constant $=6.63 \times 10^{-27} \mathrm{erg} . \mathrm{sec}$,

$v_{\mathrm{T}}=$ frequency of the TCP $=7.466 \times 10^{10} \mathrm{cps}$,

$\lambda_{\mathrm{T}}=$ wavelength of the TCP radiated by the radiant

mass of the universe $=$ hc $/ \mathcal{E}_{T}=0.4018 \mathrm{~cm}$.

\subsection{Interpretation of Consciousness and Prâna ('Vital Living Force')}

Pal et al $[1,3]$ showed that the quantized energy $\left(\varepsilon_{T}\right)$ of TCP is responsible to cause the universal consciousness as well as the cosmic microwave background radiation temperature. The individual consciousness owes its origin to the universal consciousness created by the same $\varepsilon_{T}$. The same $\varepsilon_{T}$ is the energy responsible for generating thought force $\left(\mathrm{T}_{\mathrm{F}}\right)$. This thought force $\left(\mathrm{T}_{\mathrm{F}}\right)$ being an expression of the universal consciousness is applicable to any inanimate object as well as to any biological system (having thinking ability). Thus the thought force $\left(\mathrm{T}_{\mathrm{F}}\right)$ being an expression of the universal consciousness exerts its functions both in vitro and in vivo.

The "Prâna" is the grosser form of the thought force $\left(\mathrm{T}_{\mathrm{F}}\right)$ itself with all its characteristics. Thus, all the functions of Prâna are liable to be governed by the quantum mechanical activities of these TCP in the inherent presence of TRP. This Prâna is the 'gross origin' of all the prevailing fundamental fields along with the 'vital living force' which controls all the psychological as well as the physiological functions of all living beings of the universe.

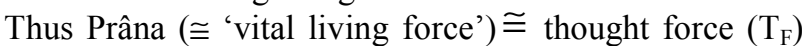
in vitro + thought force $\left(\mathrm{T}_{\mathrm{F}}\right)$ in vivo $+\mathrm{T}_{\mathrm{F}}$ (micro) $+\mathrm{T}_{\mathrm{F}}$ (macro).

Fritjof Capra [13] expressed, "The Indian concept of 'Prâna' and the Chinese concept of ch'i are to be taken into account as examples of traditional terms referring to these 'subtle energies', or 'life energies'. The sum-total of the energy displayed in the universe is called Prâna indicated by Vivekananda [14]. This Prâna is thought to be the 'universal power'.

Note: Prâna (prāṇa) is the Sanskrit word for "life force"; in yoga, Oriental medicine, and martial arts, the term refers to a cosmic energy believed to come from the sun and connecting the elements of the universe. The universal principle of energy or force, responsible for the body's life, heat and maintenance, prana is the sum total of all energy that is manifest in the universe. This life energy, Prâna has been vividly invoked and described in Vedas. In Ayurveda, tantra and Tibetan medicine "praṇā vāyu" is the basic vāyu (wind, air) from which all the other vāyus arise.

As per the BHAGAVAD-GITA (Translation and commentary by Veeraswamy Krishnaraj), Prâna is not mere breath; it is more. First we should not consider Prâna only in the context of physiological respiration: exchange of oxygen and carbon dioxide in the lungs. It is life; it is movement; it is being; it is nourishing; it is the primal force; it is energy. Prâna encompasses all energies discovered and yet undiscovered: it is thought, it is motion, it is gravity, it is lightening, it is energy in the atom, is the motion in the atoms, it is juice in everything. Any discovered or undiscovered energy in our body or in the universe is Prâna, call it by any name----respiration, nerve conduction, thought, gravity, magnetism. All forces originate from Prâna and all forces subside in Prâna.

\section{Discussion}

Fritjof Capra [13] expressed that Mind and life have become inseparably connected, with mind-or, more accurately, mental process---being immanent in matter at all levels of life. It has been obvious that getting sick and healing are both integral parts of an organism's selforganization. Since all self-organizing activity is mental activity, the processes of getting sick and of healing are essentially mental processes. Because mental activity is a multilevel pattern of processes, most of them taking place in the unconscious realm we are not always aware of how we move in and out of illness, but this does not alter the fact that illness is a mental phenomenon in its very essence. Hence it is apparent that all disorders are psychosomatic in the sense that they involve the continual interplay of mind and body in their origin, development, and cure.

In our view, the evolution of life and consciousness is possible due to the inherent existence of universal consciousness and also due to the directive of the Universal Mind (UM), the functional state of which is the universal consciousness. The UM is shown here to be constituted by these TCP and TRP in the inherent presence of thought force $\left(\mathrm{T}_{\mathrm{F}}\right)$ in vitro and thought force $\left(\mathrm{T}_{\mathrm{F}}\right)$ in vivo. It is possible that the quantum mechanical activities of these TCP and TRP are responsible for creating RNA/DNA to evolve life as well as consciousness.

The "Prâna" is the grosser form of the thought force $\left(\mathrm{T}_{\mathrm{F}}\right)$. Thus, all the functions of Prâna are liable to be governed by the quantum mechanical activities of the TCP in the inherent presence of TRP. This Prâna is the 'gross origin' of all the prevailing fundamental fields along with the "vital force'. It is probable that the TCP itself would be found to be the exact force-carrying particle responsible for this specific "interaction" called "Prâna".

\section{Conclusion}

We have shown that $\varepsilon_{T}$, the quantized energy of TCP ultimately represents consciousness. The same $\varepsilon_{T}$ is the energy responsible for generating thought force $\left(\mathrm{T}_{\mathrm{F}}\right)$.

We have shown here a relationship between

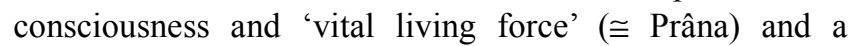
relationship between the vital living force and thought force.

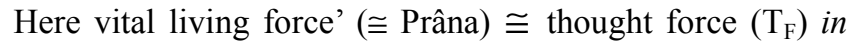
vitro + thought force $\left(\mathrm{T}_{\mathrm{F}}\right)$ in vivo $+\mathrm{T}_{\mathrm{F}}($ micro $)+\mathrm{T}_{\mathrm{F}}$ (macro) . 


\section{References}

[1] D. Pal and A.U. De, Physics of consciousness and its model may provide guidelines to solve Many scientific problems. Neuroquantology 1: 17-28(2004)

[2] D. Pal and A.U. De, Consciousness model: Significance of thought-carrying particles and thought-retaining particles in quantum measurement as well as cognitive problem. Neuroquantology 2: 115-116 (2005)

[3] D. Pal and A.U. De, The cosmic microwave background radiation temperature signifying the existence of the thought-carrying particle, thought retaining particle and thought force. NeuroQuantology 10: Issue3; 428-442 (September 2012)

[4] M. Bhaumik, Code Name GOD. (Penguin Books India Pvt. Ltd., 11 Community Centre, Panchsheel Park, New Delhi 110017 , India) pp. 132-133; 161-162; 167; 171; 177; 183 and 184. 185-186; 89-190; 198 (2006)

[5] Dhananjay Pal, Existence of Thought Force and Its Characteristics, American Journal of Physical Chemistry. Vol. 2, No. 5, 2013, pp. 94-104. doi: 10.11648/j.ajpc.20130205.13

[6] V. F. Weisskopf, The Origin of the Universe, The World of Physics, (Simon and Schuster, 1230 Avenue of Americas, New York 10020) 3, pp. 10 and 314 (1987)
[7] .D. Pal, Existence of universal consciousness and its characteristics. Accepted for publication in 2014 International Conference on Advanced Education and Management (ICAEM2014) Beijing, China (2013)

[8] I. Prigogine and G. Nicolis, Self-Organization in NonEquilibrium Systems. (Wiley 1977) ISBN 0471024015.

[9] R. Nelson, Director, Global Consciousness Project, Princeton, New Jersey. (2009) rdnelson@princeton.edu

[10] D. Radin, The Conscious Universe: The Scientific Truth of Psychic Phenomena. (Harper Edge) (1997) ISBN 0-06251502-0.

[11] R. Penrose, Shadows of the Mind: A Search for the Missing Science of Consciousness. (Oxford University Press) (1994)

[12] W. Van De Bogart, Earth portals: Exploring New Metaphors of Consciousness 1993 willard@earthportals.com

[13] Fritjof. Capra. Uncommon Wisdom. Flamingo, An Imprint of Harper-Collins Publishers. 1989; p- 159 and 216-217.

[14] Vivekananda. RAJA-YOGA, The complete works of Swami Vivekananda, Advaita Ashrama.1989; 1: p-223; ibid.; PRANA, 1: p-147- 173. ibid.; The Cosmos (the Microcosm); 2: $\mathrm{p}-212-225$.

[15] Dhananjay Pal, Possible Bridging the Classical Physics and Quantum Physics through Consciousness, American Journal of Modern Physics. Vol. 2, No. 6, 2013, pp. 322-329. doi: 10.11648/j.ajmp.20130206.18 